In the treatment, we made a liberal use of laxatives and quinine. Purgatives, particularly irritating purgatives, were seldom administered by us. They seemed to be in nowise necessary, and, in some cases, might be productive of much injury.

We have stated that the results of the treatment of the diseases of the Isthmus of Panama were favourable, as far as our observations extended. What were those results ? every reader will ask. The hospital record, to which we have so frequently referred, affords a satisfactory answer.

Of the 382 patients, 8 died of the following diseases, viz. :Tuberculosis of the Lungs and Climate Fever, . 1

Climate Fever and Delirium Tremens, . . . 1

Climate Fever and Enteritis, . . . . 2

Debility consequent upon Congestive Fever, . 0

Erysipelas and Dysentery, . . . . . . 1

Chronic Dysentery and Splenitis, . . . 1

Congestive Fever, Enteritis, and Dysentery, . 1

Congestive Fever occurring during Convalescence, 0

From Dysentery,

In the preceding pages, we have not endeavoured to present a systematic treatise upon the fevers of the Isthmus of Panama, but to record, in an intelligible manner, some of the results of personal observation in a new.and extensive field.

The length to which this paper has already been extended, makes it necessary to reserve our account of Dysentery, Diarrhœa, Hypertrophy of the Spleen, \&c., for a future article.

ART. VIII.-On the Injurious Effects arising from the Manufacture of Lucifer-Matches, as observed in the Neighbourhood of Manchester. By JAMES BOWER HARRISON, M.R.C.S.E., formerly Surgeon to the Ardwick and Ancoats Dispensary, \&c.

\title{
INTRODUCTORY REMARKS.
}

[In the sixty-sixth volume of this Journal, July 1846, there was given a short account of a form of Nekrosis affecting the maxillary and the jaw bones in persons employed in the manufacture of lucifer-matches. The disease had been first described, if not observed, in 1844, by Mr Lorinser, surgeon to one of the civil hospitals in Vienna; and its occurrence is ascribed to the poisonous action of the vapours of phosphorus. It took place chiefly among females varying from nineteen to forty years of age; and at the dif- 
ferent manufactories at Vienna at that time, nine wellmarked cases had been furnished.

In five of these cases the disease was seated in the upper jaw ; in the remaining four it attacked the lower jaw. Of these nine cases five died, one was cured, and three were at the time of the account published by Professor Heyfelder of Erlangen, in 1845, in a state of convalescence.

Heyfelder, to whom we are indebted for these facts, states that the disease has been also observed among the workers in the lucifer-match manufactories at Nuremberg. Nine cases were furnished by one manufactory alone. The patients were females from fifteen to twenty-seven years of age, some married, others unmarried. All had previously enjoyed good health, and they had spent about fifteen hours daily in the manufacture of phosphorous matches. In four of these nine cases the disease attacked the upper jaw, and in the remaining five it attacked the lower jaw. Only two persons recovered; one after the spontaneous separation of the alveolar portion of the upper jaw; the other after having the lower jaw removed by operation. Six persons of the nine died; and in two of these the lower jaw was removed by operation. ${ }^{1}$

At this period Professor Heyfelder published a good example of the disease, which it may be proper here shortly to reproduce.

On the 7th of June 1843, Margaret Rumpler, aged twentyone years, came into the clinical surgical establishment of Erlangen, in order to be treated for a disease of the lower jaw. For several years she had acted in a manufactory of lucifer matches as overseer of the workwomen engaged in dipping the matches in phosphorus and drying them. At first she was attacked in the teeth with severe pain, which was afterwards communicated to the lower jaw. Several teeth had become loose, and had been removed.

Upon admission the left side of the face was swelled and undermined by sanious fetid purulent matter. There were several openings by which it was possible to touch the lower maxillary bone, which was entirely denuded of soft parts. The teeth were gone, aud the alveoli were no longer covered by the gums. The matter which flowed from the sinuses was sanious and fetid; salivation was greatly increased; the appetite was feeble, digestion bad, the pulse quick. The complexion was of a straw-yellow colour.

At the age of eighteen years, this girl had suffered from

1 Edinburgh Medical and Surgical Journal, volume sixty-sixth, p. 254. Edinburgh, July 1846; and Archives Generales de Medecine, Tome lxix. Octobre 1845, p. 204. 
rheumatic disorders. But she had never laboured under any symptoms of syphilitic disease. Menstruation had always been regular.

On the ninth of June 1843, Professor Heyfelder removed the diseased half of the maxillary bone at the articulation. The cure proceeded so speedily that the patient left the hospital on the $22 \mathrm{~d}$ of June. Immediately afterwards she returned to her former occupation, namely, the inspection of the workwomen occupied in drying the matches after being dipped in phosphorus. At this, however, she remained only a short time; for in the month of March 1844, she returned to the hospital in a deplorable state. Not only the other half of the lower jaw, but the superior maxillary bone of the right side was attacked by the disease, for which nine months previously she had solicited assistance.

It was in the month of January 1844, that she perceived the first symptoms of this second attack. Notwithstanding this she continued to attend to her occupations until the 13th of March. At this period she was so severely afflicted, that she was unable to maintain the erect position or to work. She was kept in the hospital for two months, during which baths and poultices were administered, iodide of potassium was given, and subsequently cod-liver oil, and the decoction of Zittmann, without quicksilver, were employed; but all without the smallest degree of benefit. Being unwilling to subject herself to a second operation for the removal of the other half of the lower jaw, and the superior maxillary bone, she preferred to return home, where she died.

Upon inspecting the body, tubercular excavations were found in both lungs; and the maxillary bones and frontal bone were in a state of nekrosis.

A minute description of the condition of both jaws is given in the treatise of Drs Von Bibra and Geist, to be immediately mentioned. But it is sufficient to notice briefly the following circumstances.

The portion of the inferior maxillary bone which had been removed, presented several peculiarities. The alveolar portion of the bone was neckrosed as far as the last molar tooth, which had not yet come completely out of its socket. The other teeth were wanting. Excepting the two processes, the two surfaces of this bone were covered by a new layer of bony matter. On the anterior surface this bony layer presents a greyish porous aspect; and several openings variable in size, by which the probe may be passed to the interior of the bone. ${ }^{1}$

1 Archives Generales de Medecine, Tome 1xix. Octobre 1845. 
At a subsequent period, Professor HeYFELDER had occasion to examine the other half of the jaw-bone of this young woman, and found it to present the same alterations.

Professor HeYFELDER subsequently published, in the Quarterly Journal of Roser and WUNDERLICH for 1845, two cases treated by himself, and Professor Dietz in Nuremberg. At the twenty-third meeting of the Association of Cultivators of Natural Science, held at Nuremberg, he read an Essay on the Lesions of the Jaw-Bones, and thereby gave rise to an animated discussion upon the Pathology and the Etiology of this subject.

On the last day of this meeting at Nuremberg, it happened that a patient died under this disease of the jaw ; and Professor HEYFELDER availed himself of this occurrence to make some further observations, chiefly anatomico-patholigical, which were published in the Medicinischen Zeitung of the Association for Medicine in Prussia for 1845, No. 45.

Subsequently to these contributions by LORINSER and HEYFELDER, not a few observers have communicated either cases or general observations. Of these the principal are the following.

Dr W. Neumann, Practical Physician in Berlin, upon the Nekrosis of the Jaw-Bones of the Phosphorous match makers. Medicinische Zeitung des Vereins für Heilkunde in Preussen. Jahrgang xv. 1846, No. 28, 30, and 31. With details of Eight examples of the Disease.

HUBBAUER, Surgeon of the First Division at Ludwigsburg, in the Medicinischen Correspondenz-blatt des Wurtemberger Arztlichen Vereins, Band xv. Jahrgang 1845, No. 36. Upon two cases of Nekrosis of the Upper Jaw, from Phosphorous Vapours; and Regimental Surgeon Dr HAIMERDINGER upon a third case.

Pluskal, Ch. M. in Lomnitz, in the Austrian Medicinischen Wochenschrift, Jahrgang 1846, No. 30, relates a case of Nekrosis of the Lower Jaw observed in a child, which had arisen from frequent lighting of many Lucifer Matches.

RoDER, apothecary in Lenzburg, Kanton Aargau, made in June 1846 a proposition for preserving the workers in Lucifer Match Manufactories from becoming attacked by disease. DingLeR's Polytechnisches Journal. Jahrgang 1846. Erstes Juni Heft.

Dr LoRenz Geist, of whose labours we shall immediately speak more fully, made known in 1846, in a small Article published in the Medical Correspondence Sheet of Bavarian Physicians for that year, two cases of disease of the Jaw observed by him, and endeavoured therein to prove that the 
original seat of the disease must be sought in the periosteum. ${ }^{1}$

Little doubt can be entertained, from the phenomena, cause; and effects of the disease, that this idea is perfectly well founded, so far as relates to the disease in the bones of the face.

These were all the writings on the subject which had been made public by the physicians of Germany up to the year 1847.

By the physicians of France the following writings were communicated to the profession.

Strohl, Assistant to the Faculty of Medicine; Note on a peculiar form of Nekrosis of the Maxillary Bones, produced in the Manufactories of Lucifer Matches; read to the Society of Medicine on the 7th August 1845. Gazette Medicale de Strasbourg, fifth year, Nos. 11, 20, November 1845.

Sedillot ; Comptes Rendus des Seances de l'Academie Royale de Science de Paris, Marz 1846 ; reports three instances of Nekrosis of the Upper Jaw. Noticed in Neumeister's Neues Repertorium, Jahrgang 1846 ; Chirurgie, No. 8.

Bricheteau, in Paris, gives, in a letter to the Editor of the Journal de Medicine, fourth year, Marz 1846, Notices upon the Increase of Diseases of the Jaws.

Rousselu, Th.; Researches upon the Diseases of the Workmen employed in the Manufacture of Lucifer Matches, \&c. Memoire presenté a l'Academie des Sciences, le 16 Fevrier 1846.

DUPASquier, M. Alphonse; Professor of Chemistry at the School of Medicine at Lyons, former Physician to the Hotel Dieu, \&c. ; On Phosphoretted Vapours, and their effects upon the Workmen employed in the Manufactories of Phosphorus, and the Workshops in which Chemical (Lucifer) Matches are prepared. Memoir presented to the Academy of Sciences ; Meeting of 31st August 1846. Gazette Medicale de. Paris, 1846, No 49.

All the observers above mentioned directed their attention particularly to the lesion in the bones of the upper and lower jaws. GENDRIN, alone, in Paris, had occasion, after RousseLL, to observe in the workers at the lucifer-match manufactories an inflammatory disorder of the bronchial mucous membrane, shewing itself by peculiar symptoms; and DUPASQUIER is the only person who, keeping in view, in a particular matter, the etiological agents, believes that this is to be found not in

1 Medicinischen Correspondenz-blatt Bayerischer Aerzte. Jahrgang 1846. Nos. 13-17. 
the phosphorus or its vapour, but in the arsenic with which the former is often adulterated. It will be seen that the first-mentioned proposition, that relating to the affection of the bronchial membrane, and it may be added in certain cases, the lungs, have received, as full confirmation as is necessary to shew that it is well founded. The second proposition may be considered as still in a state of probation.

This disease seems to consist in or to depend upon the action of the phosporetted vapours upon the bones of the upper and lower jaw, and their periosteum. Fatal cases are said to exhibit symptoms of pulmonary consumption.

In the year 1847, Drs Ernest Von Bibra, and Lorenz Geist published at Erlangen an express treatise on the diseases of the workers in the lucifer-match manufactories. Of this work, which contains full and detailed accounts of the disease, its origin, its symptoms, and its effects, with profitable suggestions for its prevention, it has been our intention to give some account. Various circumstances, however, have concurred to prevent us from doing so. ${ }^{1}$ At present we can only advert to some of its most important contents.

Notwithstanding the list above given, $\mathrm{Dr}$ Lorenz Geist thinks that the number of observers of this disorder is still small ; and he remarks, that, in France especially, the lesion of the lower jaw has been seldom seen, and consequently has been little the subject of investigation. Assuredly, if we consider the great number of lucifer-match manufactories in Paris, and the populous and industrious cities and towns of France, it must be allowed that much less, comparatively, has been done to make known and elucidate the disease of the lucifer-match makers in France than in Germany. It is particularly in Vienna, Berlin, and Nuremberg, that most of the cases have been witnessed, and their effects recorded. It is principally upon morbid specimens of the diseased parts derived from these cities, that the microscopical and chemical inquiries of Von Bibra have been made. This physician has examined, in the manner now specified, seven lower jaws and three upper jaws, which had been the seat of the lucifer-match disease.

It is not, however, either by microscopical inspection or by chemical analysis, that the characteristic nature of diseases is in all instances elucidated. Observation of symptoms

1 Die Krankheiten der Arbeiter in den Phosphorzündholtzfabriken insbesondere das I Ieiden der Kiefer Knocken durch Phosphordampfe Bearbeitet. Von Dr Freiherrn Ernest Von Bibra, und Dr Lorenz Geist. Erlangen, 1847. 8 vo. 
during life, and examination of the state of parts when life has ceased, are, if not always, at least in the greater part of diseases, necessary to enable the physician to understand, and instructively to explain to others, the nature of the morbid action; while attentive and sedulous observation of the eircumstances in which diseases arise, is quite indispensable, in order to form just ideas of the peculiar causes on which they depend. The accomplishment of a plan of this kind, says Dr Lorenz Geist, demanded the combined efforts of the physiologist and the physician, and the result of the connection of the two is the work of Dr Von Bibra and his associate.

Among other inquiries, Dr Von Bibra undertook to ascertain the mode in which phosphorous vapours operate upon the lower animals. One of the results of this inquiry seemed to be, that the disease does not consist in a simple necrotic process, though the lesion was in its commencement periosteal inflammation. This, he thinks, is proved by the peculiar phenomena which manifested their presence in the animals exposed to phosphorous vapours, not only in the bones, but also in the soft parts, as well as the necroscopic appearances found in the bodies of the workwomen, cut off after the acute form of the disease.

The diseases, to which the workers in lucifer-match manufactories are exposed, may be distinguished, according to the best observations hitherto made, into two principal tribes.

These are,

I. An Inflammatory Affection of the Mucous Membrane of the Lungs ; Bronchitis, and habitual Cough ; Gastric symptoms.

II. A Peculiar Disease of the Jaw-Bones, not hitherto determined in its nature; both tending, in all cases hitherto observed, to Nekrosis.

I. The inflammatory disorder of the Bronchial Membrane has been described principally by the physicians of France.

Since the origin of lucifer-match manufactories, from time to time there have been received from these establishments, workers, mostly females, who were employed in the business of dipping the wood matches in the mass of phosphorus. Among the patients, also, were males, whose duty consists in rubbing the combustible substances. All these patients agree in making the statement, that, from the date at which they entered the manufactory, they were attacked by cough. They then in general first applied to the hospital for assistance, when the cough had become habitual, was aggravated and complicated with all the symptoms of acute Bronchitis. The Bronchitis differs not in its essence from that which

vol. LXXIX. No. 194. 
takes place in ordinary circumstances ; but it is complicated with simultaneous functional disorder in other organs. Even those patients who are attacked in slight degrees, are in a remarkable state of weakness; they complain of loss of appetite, by which they represent themselves to have been attacked immediately at the commencement of working, and at the same time with the cough. Others are afflicted by diarrhœa. The greatest part present febrile symptoms, even when an inflammatory pectoral disorder is not yet recognised. Those who are ofttimes attacked by inflammatory pulmonary catarrh,- and these are the majority,- - are remarkably emaciated, suffer sometimes from palpitation of the heart, yet without the heart or the large vessels being themselves diseased.

This assemblage of symptoms, which is not peculiar to ordinary bronchitis, must accordingly be ascribed to the poisonous operation of the phosphorous vapours received by the lungs, and probably also through the skin and the mucous membrane of the alimentary canal.

The patients hitherto treated have all been cured; at least the urgent symptoms were alleviated. The remedies consisted in those usually employed against bronchitis, as also in emetic and purgative medicines, the exhibition of which is indicated by the gastric symptoms. The disease was in general always tedious; almost all the workers had been, with short intervals, repeatedly attacked by acute bronchitis ; and after each relapse there was left a chronic form of bronchitis of a worse character. This chronic disorder, as also the irritability of the bronchi, maintained and aggravated by the operation of the phosphorous vapours, partly explains the obstinacy after each relapse, with which the disease resists the operation of remedial measures.

Though these patients are cured, it must not thence be concluded, that the disease is less severe. Though all the symptoms of acute bronchitis be allayed, and the functions of the digestive tube are restored, yet the constitution of the patient is undermined. Sufficiently often emphysema of the lungs and great tendency to relapse is left.

Two cases are subjoined illustrating the symptoms, course, and treatment of the disease.

In the second of these, which took place under Gendrin, that physician makes the remark, that almost no lucifer-match maker with intense chronic bronchitis can be completely cured, because the circumstances in which they are placed, present great difficulties in effecting a cure. The bronchitis of the lucifer-match makers, though at the beginning acute, becomes chronic from the continuance of the exciting cause, 
and brings the majority of these persons, by repeated attacks of acute bronchitis, to an early death.

Quite similar severe cases were observed by Strohl at Strasburg, and Lepine at Chalons-sur-Saône.

Among the German physicians no inflammatory symptoms of equal severity to those cases which have been adduced by Gendrin have been mentioned as the consequences of the operation of phosphorous vapours. Neumann, however, says that the workers, before they have become accustomed to the phosphorous vapours are attacked by inflammatory pectoral disorders, and that in many appear gastric sufferings, which, however, under slight treatment, or even without medical assistance, disappear without further consequences. Three persons were destroyed by pulmonary consumption, the development of which, with a previously present disposition, appears to have been accelerated by inspiring the vapours of phosphorus.

It is nevertheless singular, that neither in Vienna nor in Nuremberg has this exquisite and complicated form of bronchitis been much observed. Lorinser, though he thinks that the phosphorous vapours enter the blood, and poisoning it generally, then act specially upon the bones of the upper and lower jaw, nowhere speaks of bronchitis in the form noticed by Gendrin.

Dr Geist states, that after visiting the manufactory at Nuremberg, he found many of the workwomen healthy and of good appearance, though many of them had been exposed to phosphorous vapours for a whole year. Of several, however, he allows that the appearance was pale and cachectic; but he adds that this aspect is not uncommon in these manufactories, and is connected with other influences different from these vapours.

He gives, nevertheless, one instance in a man, aged fiftytwo, who had been three-quarters of a year engaged chiefly in the dipping process. This man recovered under treatment, did not return to the manufactory, and was three years subsequently in perfect health.

The most frequent form of the disease in the cities and towns of Germany as hitherto observed, is certainly the affection of the upper and lower jaw-bone. Of this affection sixty-eight examples have now been recorded, and of these a tabular view is given by Dr Lorenz Geist, while the authors give the histories of twenty-three cases, several of which were not previously published. Of these sixty-eight cases, twenty-two took place in Vienna, fifteen in Nuremberg, eight cases in Berlin, two in Ludwigsburg, and two in Lomnitz. 
These forty-nine cases were the whole known in Germany in 1847. Three took place in Strasburg, making fifty-two cases. All the Vienna, Nuremberg, and Berlin cases took place in females. Two of the Ludwigsburg and Lomnitz cases occurred in men. Six other cases were afterwards observed by Drs Von Bibra and Geist; and one case was communicated to them by Dr Kolbe of Stuttgart. All these six cases took place in females between the ages of sixteen and twentythree. The case of Dr Kolbe occurred in a woman of thirty three.

Among the whole sixty-eight cases only five took place in men. It might be inferred from this that males were less liable to be affected. This conclusion, however, would be far from being correct. The small number of males attacked depends upon the small number of men employed in these manufactories. The greater part of the operations are performed by females. And if the number of men attacked be compared with the number of men employed, the proportion will appear, Dr Geist is persuaded, not materially different. He thinks, therefore, that it is a legitimate inference to say that the disease spares neither sex nor age. We further find, that of these sixty-eight cases, fifteen persons recovered, fifteen died, fifteen were under treatment; and of twenty-three cases the issue is not known. Of the fifteen cases of recovery, those which took place at Berlin are distinguished by a large proportion of success, in so far as among eight instances of the disease seven recovered.

Among fifty-four instances there were twenty-three of disease of the upper jaw, twenty-six of the lower jaw, and five instances in which both jaws were affected.

These numbers shew a very slight predominance in favour of the lower jaw.

We would with great pleasure give more ample details from this elaborate and instructive work. But this our limits and present object forbid. It is sufficient at present to direct attention to the only complete treatise that has yet appeared on this subject, in connection with the essay by $\mathbf{M r}$ Harrison. We shall, however, endeavour to find opportunity to place before our readers some of those results which the researches of Drs Von Bibra and Geist have furnished.

Meanwhile it may be at once interesting and instructive to direct attention to the observations of $\mathrm{Mr}$ Bower Harrison on the same disease as it is seen in Manchester, and the observations on it as it appears in the workers in two lucifermatch manufactories in Dublin.] 
new branch of trade, it is important that its effects upon artisans should be properly understood, and every means afforded them of protecting their health and their lives. It will be found, that when the trade is practised under disadvantageous circumstances, the most formidable and appalling evils arise from it. An affection ensues, which is so insidious in its nature, that it is at first supposed to be a common toothache, and a most serious disease of the jaw is induced before the patient is fully aware of his condition. This disease gradually creeps on until the sufferer becomes a miserable and loathsome object, spending the best period of his life in the wards of a public hospital, and these evils are incurred for a remuneration as small as that of six or eight shillings per week. It will be seen that most persons quit the employment before the disease has proceeded far, so that the employers are not always aware of the extent of the mischief. Many patients have died from the disease; many, unable to open their jaws, have lingered with carious and necrosed bones; others have suffered dreadful mutilations from surgical operations, considering themselves happy to escape with the loss of the greater portion of the lower jaw. That such results call for the investigation of the surgeon, there can be no doubt, and it equally becomes the duty of society to give a proper consideration to the information which is afforded.

My attention was first directed to this subject during a visit which I paid to the Manchester Infirmary, where I saw a young female suffering from the complaint. She would have been good-looking if it had not been for the foul disease of the jaw. I was told at the hospital, that forrteen patients could be enumerated, who, in the space of a few years, had been admitted with the same disease, and, I believe, from the same manufactory. I do not imagine that the evils which attend the manufacture of lucifer-matches are commonly known, and I am very sure that it is necessary they should be so. I think it would be well if the manufactories in which the trade is carried on were subjected to suitable inspection and stringent regulations. How great is the importance of the ventilation of these places will, I think, appear in the sequel. I trust, however, that the results which I am about to describe are those of exceptional cases; but it is still proper that such exceptions should be known. I do not wish to censure those engaged in the trade. Some, I am aware, who had entered upon it without a full knowledge of its consequences, are now seeking to ameliorate the condition of their work-people. I wish rather to make it apparent that these matters should not be left to the know- 
ledge or benevolence of individual manufacturers; for who can say how many ignorant persons may yet embark in the trade? Who can say how many persons of limited capital may commence the manufacture in small and ill-ventilated chambers. The soldier is not forgotten by a grateful country, and shall the sons and daughters of industry perish ignominiously by the labour of their own hands?

When I thought of inquiring into the extent of the mischief which resulted from the manufacture of lucifer-matches in this neighbourhood, I obtained some particulars from patients who had been formerly treated in the Manchester Infirmary. As most of the sufferers had, however, been removed to their own homes at some little distance from the town, I could not readily collect all the information I desired, particularly as the weather was extremely wet at the time, and I became unexpectedly engaged with other important occupations. I am happy to say that the operatives with whom I obtained an interview made no reproachful allusions to the nature of the employment, and spoke in a modest and resigned manner, that would have done credit to the most educated of men. I have given the statements of the patients, without any pretensions to offering full details of their cases, and much in the way that the evidence of a witness might be recorded; the repetitions which occur have been purposely suffered to remain, and I have confined myself chiefly to such remarks as appear to elucidate the effects of the employment. It was my original intention to have spoken of all the fourteen cases, but the few I have given may, in the present instance, be sufficient.

CASE I.-Anne MacVie, aged 20, was occupied four years before she suffered from her employment. Her teeth were previously good; her complaint began like ordinary toothache, and was considered by her as such in the commencement. She was occupied only in putting the lids on the boxes. At first she could perceive the smell of the preparation, but afterwards she became insensible to it; she stated that her clothes, as well as her hands and arms, were incandescent at night; she had enjoyed good health previously to being engaged in the occupation, and had been employed in a silk factory. She had not taken her meals in the lucifer-match factory, and had always been in the habit of washing her hands, and attending to personal cleanliness. When she uncovered her face I perceived that the lower jaw was nearly deficient, and at the side of the jaw were two or three large holes. Mr Jordan had removed the jaw, at the Manchester Infirmary, about seven years ago (January 1852). She is now occupied in putting labels on boxes; her wages had 
been six shillings per week. She is of a pale and scrofulouslooking appearance; she had been accustomed to have meat daily, at least as much as her wages would admit of. She said that she had no gathering about the tooth in which the disease began, but that the complaint was at first like common toothache ; she resides in the Droylsden Road, Newton Heath. She says that many of the work-people take their meals in the work-rooms.

(The matches made are of wood. The dippers dip the matches in bundles into the preparation contained in iron bowls, and they are afterwards spread out to dry.)

She was seven months in the Infirmary; altogether her appearance is a sad spectacle. She had no salivation previously to the disease of the jaw, but afterwards a profuse one; she cannot now chew anything that is not quite soft. Says she works at what the people term " piece work," that is, she obtains remuneration according to what she does, it being sometimes six, sometimes seven, and sometimes eight shillings per week.

CASE II.-Margaret Burns, resides at Newton Heath, next to MrWoolstencraft's timber-yard ; aged 23; employed about two or three years previously to her suffering from the occupation. Her department was that of picking (sorting) the matches previously to their being put into boxes after they were dipped. She had good teeth before entering on this business ; the complaint began like ordinary toothache, for which she had one tooth extracted; - but the gum afterwards gathered and discharged outside. She could at first smell the peculiar fumes, but not after a time; she had good health before she entered the employment; she did not take her meals in the work-place, but at home, as she did not live far off. It is now (January 1852) four years since she was affected; she had not been in any occupation before entering the factory; she always twashed her hands before her meals, and was attentive to cleanliness. She had heard something of the injurious nature of the work before she commenced it, but conceived that the reports were exaggerated, and that she should escape. She obtained from seven to eight or ten shillings per week, according to what she did; she states that formerly the business was carried on in two rooms, but that now they were thrown together, and all worked in the same room, which did not smell so bad as each did formerly. She is not of a scrofulous appearance, and would be goodlooking if it were not for her complaint.

The lower part of the face is much altered by the loss of the greater portion of the jaw, which gives a peculiar cast to 
the countenance, the natural oval of the face being destroyed. She had been in the habit of getting meat daily, and had previously, and now has, good health, irrespective of the state of the jaw. She was taken to the workhouse after the appearance of the complaint, where she was under the care of the resident surgeon for one year and a half. She said she underwent three operations at the workhouse; she was subsequently four months in the Manchester Infirmary, where she says Mr Jordan performed two operations. She was not subject to cough, and suffered in no other way than from the jaw; but she states that some persons in the occupation suffered from coughs, but she believed them to be naturally subject to such affections; her appetite was not affected by the employment. The lower jaw seemed nearly all absent, and presented a shocking and revolting appearance; even at the present time (January 1852) it is not properly healed; she had no salivation before the jaw became diseased, but afterwards a profuse one; she is obliged to live on soft food, and cannot chew anything not previously crushed and made soft. She is now employed in making boxes, and is out of the way of the fumes; for her present occupation she obtains about six shillings a week. The disease commenced in a tooth at the right side, and gum abscesses formed about it. This girl, like the other, is, as regards appearance and comfort, quite ruined for life; she said that she suffered so much that she often wished to destroy herself.

CASE III.-Joseph Johnson, aged 21. His face looked swollen and distorted, and on one side was the mark of a deep, round ulcer; he had worked six years in the occupation before he began to suffer, the complaint then came on like toothache; he does not believe he had any decayed teeth prior to his entering the occupation. He was a dipper, and held his face over the heated preparation; he worked from 6 in the morning until half-past 7, dipping all the while; had good health previously. When the disease commenced he came to the Infirmary at Manchester; he has now no teeth in the lower jaw, which is in a great measure destroyed; he did not take his meals in the place. He obtained fourteen shillings per week for what he called piece-work, that is, he was paid in proportion to what he did. He mixed the preparation as well as dipped the matches. He says that the preparation is composed of phosphorus, chlorate of potash, and glue, the matches being previously dipped in sulphur; the matches are of wood. He says that he was particular in washing himself, \&c.; that he did not know of the injurious effects previously to his entering the manufactory; says that he stood all day, except at meal times, i. e., from 6 A. M. to 7 
P. M.: he lived near the establishment, and could smell the fumes even out of the building when the wind blew in a favourable direction; during all the period of his occupation he could smell the odour of the preparation; his clothes became incandescent with it; and the rooms in places looked like white smoke; he had a good appetite whilst in the occupation, and was well in all other respeets, not having cough, \&c. Says he knows of fourteen who have suffered from the work, all residing at Newton Heath, and that two died. $\mathrm{He}$ had pains in his knees from long standing, and the knees became in some measure crooked with it; he is well now, but cannot chew anything hard; he works at present in making cases for packing up, for which he obtains 8s. 6d. per week; he works from 6 A. M. to half-past 7 P. M. ; he had salivation after the disease set in, but not before it; he cannot say that his taste was affected, or that he perceived the phosphorus in his mouth. Does not think the place is damp; none of the people made any reflection on the master.

CASE IV.-Anne Farrell, aged 19, at present in the Manchester Infirmary with diseased jaw. This young woman said she got remunerated according to the work she did, which did not bring more than seven or eight shillings per week ; that she was engaged in separating the matches; that she was not aware of having any decayed teeth when she went to the works, but that the complaint commenced like toothache; afterwards the gum swelled by the side of the tooth, gathered, and burst; a discharge took place; the swelling then re-formed and again burst; that her face was not swelled when she left the establishment, but she left from her knowledge of what had happened to others. This was her first place of occupation; she had not previously been in any employment; she had not perceived any peculiar bad taste or odour, but this she attributed to being accustomed to the rooms ; said that formerly the rooms were very close, but that they had been lately altered so that two rooms were thrown into one; she stated that her clothes were incandescent at night; said that young men were employed in the dipping department, but that no women were employed in it; several of the former, however, had suffered.

CASE V.-Bridget Ryan, aged 15, also in the Infirmary, with diseased jaw ; formerly worked in a cotton manufactory; has been three months in the Infirmary, and had been ill four months before. The rooms were formerly close, but have lately been altered; she did not make more than six shillings per week; she had a toothache when she left; had not any decayed teeth before she went. Her occupation was to put the matches in the boxes; had been employed three years 
before her jaw became diseased. She says the rooms look incandescent when the gas is put out, and that her arms and dress were so whilst she was employed. I asked whether any precautions were taken to prevent mischief to the operatives. Thinking I was referring to precautions against fires, she stated in reply that the matches frequently took fire. When she got accustomed to the work, she did not perceive any particular taste or smell. She stated that several young men had suffered from the dipping department, in which young men were exclusively employed.

I was told that two persons had died from the occupation, one, J.D., aged 24, who was the nephew of the gentleman who kept the establishment. He had been in the Infirmary, but was discharged as incurable, and died at home. He had been employed as a dipper. Another, William Reynolds, also died at his own house, was never brought to the hospital, but was under the care of Mr Pegge; he had been employed three or four years, and was about eleven years of age; he was employed as a lapper-up.

In the establishment in which these cases occurred it seems that the work people stand during the whole day, except at meal-times, and many suffer from the state of the knees. The floor is partly of brick and partly of flag. Efforts have been made, and are still being made, to prevent the fumes from being perceptible, and the place is, in this respect, now much improved. The dippers are generally lads. The hours are from six in the morning until seven at night, with the exception of half-an-hour for breakfast, one hour for dinner, and half-an-hour for tea: all have the same hours. There were formerly two rooms, but they are now both thrown into one.

The period necessary for the production of the disease must obviously depend on various causes, particularly on the constitution of the employed, as to whether it is scrofulous or otherwise; something also will depend on the condition of the teeth, whether carious or sound; also on habits of cleanliness; and the department in which the person is engaged. It will be seen, however, to range generally from two to six or eight years; but in some cases mischief did not arise before eleven or more, so that immunity for a considerable period should not render us certain that no danger is to be apprehended. I collect the following on this point from some of the medical periodicals. Dr Strohl ${ }^{1}$ mentions several cases which occurred after various periods. The first case, which 
was fatal, happened in a female, it is stated after many years' employment.

The second also in a female, aged 24, who was a dipper; the disease came on after five years of occupation, and commenced three months after she had left, when eight teeth became rapidly carious; the upper jaw became diseased as well as the lower, and the matter (pus) had the odour of phosphorus.

The third case, a female of 22, occurred after two years' employment; her health had continued good until the last two months of her employment; the gums then began to soften and swell, violent pains came on in the teeth of the upper jaw, the teeth became carious and fell out ; a fetid suppuration arose, and the bone became extensively diseased.

The next case was likewise in a young woman of 22 . Her department was to make up parcels, but this was done in the same room where the matches were dipped; at first she experienced a defluxion from the nose; after three years the face began to swell, and she left the business; the upper jaw became carious after the formation of an abscess.

M. Sedillot, of Strasburg, relates three cases which came on after about four years, all females. One died.

In the manufactories at Vienna, cases did not occur until the employment had been pursued for eleven years.

In Mr Taylor's cases, ${ }^{1}$ the first patient, a man of 49, had been engaged eight years; the complaint commenced with pain in the upper jaw, and purulent discharge. The second, a man of 45 , had been fifteen or sixteen years in the employment; he was a kind of superintending assistant, and had the credit of being the first who introduced the trade into England; he was of intemperate habits.

Dr Ebel has furnished an account of the result of five years' experience in the factory at Waldmichelberg, as well as a digest of what had been previously written on the subject. It would seem that the factory where his observations were made was under peculiarly good management, and, in all probability, the ventilation was very perfect. There were about 200 individuals employed there, both male and female, chiefly between fourteen and eighteen years of age. The hours of occupation were from 5 to 7 , two being allowed for meals, the meals not being taken in the work-place. Attention is also paid to the health of those admitted into the establishment previously to their being engaged. There is less wonder, therefore, that the place is stated to be free from disease. It appears that caries of the teeth is common in the neighbour-

1 Lancet, vol. ii., 1849. 
hood, but not more common in the establishment than elsewhere. Out of 200 persons, 153 had some carious teeth. Dr Ebel states that the health of the persons in the factory was on the whole better than that of those who were in a similar rank of life out of the employment, and that, after a few years, an improvement was remarked in their condition. The work, he says, is not laborious, and the rooms in which it is conducted are spacious. It is incidentally remarked that some of the diseases of the locality, especially the itch, became less prevalent since the establishment of the factory, a result which may very likely arise from the sulphurous fumes. On the whole, this report is very favourable; but perhaps it is a little premature; for the proprietor does not seem to have had more than eleven years' experience. It shews, however, how much may be done by a good system of ventilation and cleanliness, with spacious rooms.?

In concluding these observations it may be interesting to notice briefly some of the suggestions which have been made for the prevention of these injurious effects.

$\mathrm{Mr}$ Henry Taylor, of Nottingham, suggests that a mask be worn over the face of the dipper, with a tube to pass out of the building into the open air, provided with valves for exhaling and inhaling, like those attached to the chloroform inhalers. ${ }^{2}$

In a report of an operation performed by Mr Stanley of St Bartholomew's Hospital, ${ }^{3}$ the writer says : "The painful feelings excited by the sight of this new victim of our vaunted improvements in various branches of manufacture were greatly mitigated by the announcement $\mathrm{Mr}$ Stanley subsequently made, regarding the prophylaxis of these dreadful affections. Workmen in lucifer-match manufactories have now a chance of escaping the baneful effects of thc evolution of phosphorous acid, by placing saucers filled with oil of turpentine about their work-rooms ; as the oil of turpentine is a solvent of phosphorus, it is expected that it will absorb the vapours which cause so much mischief. This precaution is taken at a large lucifer-match manufactory in the neighbourhood of the London Hospital, and the very best results are expected from it."

Dr Baur proposes the use of alkaline fluids in addition to other means. ${ }^{4}$

"The preventative means would consist in the following precautions.

1 Casper's Wochenschrift, 1851, Nos. 10 and 11.

2 Lancet, Nov. 10, 1849, p. $498 . \quad 3$ Lancet, Nov. 17, 1849, p. 429.

4 Nouvelle Encyclographie, Aout 1850, p. 219. 
" 1 . In preventing the phosphorated vapours from acting on the teeth by the use of a mask, or still more effectually by means of a handkerchief to which is attached a sponge soaked in water, or in an alkaline liquor, soda, or potash. By this contrivance these vapours would be prevented from reaching the nose and the mouth of the workmen.

" 2 . In the manufactories or workshops, it might be easy to have flat vessels filled with an alkaline lee, which would attract the phosphorated vapours.

" 3 . If the individuals who work at this species of labour, have stumps or hollow teeth, it would be requisite to have recourse to a dental stopping which might fill these cavities. At the same time it should be recommended to all the workmen to take great care of their teeth, to clean them frequently, as well as the face, with a calcareous or lime water liniment. This consists of lime water thirty grammes, oil of white poppy fifteen grammes."

It is possible that the use of alkaline remedies may be of some service. But I think more is to be trusted to ventilation, to the proper construction of the rooms, to a perfect separation of departments, to an abridgment of the hours of labour, and the choice of workmen and women who are not of scrofulous constitutions, and who have not decayed teeth. The habits of the work-people ought also to be carefully attended to, and no one should be allowed to take meals in the work-place. It is not unlikely also that the more injurious parts of the occupation might be rendered innocuous by mechanical contrivances which should supersede the dipping of the matches by men stooping over the fumes of melted phosphorus. But these means require not merely being known, but being enforced; and it is to contribute to such a result that I have been induced to offer the foregoing remarks.

But let me return from these details to the consideration that the poor persons whose cases I have named are still suffering from their affliction; that there are yet patients in the wards of the hospitals, who are lingering day and night with this slow and disgusting disease. Young women who were once good-looking are shut out from the prospects which marriage might have afforded, and young men who were once buoyant in health have broken their strength and spirits in struggling with a horrible disorder. Who shall take up their cause if every right-minded man does not feel it to be his own? Who shall commiserate such misfortune, if every kind-hearted woman does not remember that there is no social position so elevated as to be freed from the ob- 
ligations which charity imposes ; and none so dignified that it is not rendered more graceful by the spirit of universal love?

\section{APPENDIX BY THE EDITOR OF THE DUBLIN JOURNAL.}

[The disease thus faithfully described by Mr Harrison is of so serious a character, its prevention of so great importance with reference to a manufacture which affords useful employment to young persons at an early age, and its history so little known to the profession, that we were anxious to ascertain if it had been witnessed in this city. We therefore personally visited"the only two lucifer-match manufactories which at present exist in Dublin, those of $\mathbf{M r}$ Kelly in Clarendon Street, and of $\mathrm{Mr}$ Reaney in Upper Abbey Street. Neither of them have been in operation for more than six months; but in the former, one of the lads employed in dipping was previously engaged for a year and a-half at the same work in a factory which was in Kennedy's Lane, but is now closed; and in the *latter there are two lads, aged about 19, both of whom were for several years in one of the manufactories near Manchester referred to by Mr Harrison.

In Mr Kelly's establishmeut three different manufactures are carried on under the same roof, viz., the making of ink, of blacking, and of lucifer-matches; the building is large and well ventilated, and the odour af phosphorus, even in the room in which the matches are dipped and made up in boxes, is but trifling, and not in the least complained of by the boys, about twenty in number, who work there. The process of dipping differs somewhat from that described by Mr Harrison. The compound, which consists of glue, chlorate of potash, phosphorus, and a small quantity of camphor, the latter ingredient being used to neutralize the smell of the phosphorus, - which it does very effectually, -is first melted over a slow fire, and then poured on a heated stone slab, so as to form on it a layer of about the eighth of an inch in depth. The matches, previously tipped with sulphur, and fixed loosely in a wooden frame about two feet long and a foot wide, are dipped rapidly on the flag until their points are coated with the melted composition; both ends are thus dipped, the frame being quickly turned round in the hands of the dipper in order to effect this; the matches, which are thus, so to say, double, are afterwards cut across in the middle, being placed in bundles under a large cutting knife; to prevent ignition from the friction to which they are necessarily submitted while being cut, their tops, coated with the compounds, are moistened before 
the matches are placed under the knife. Nevertheless they constantly take fire, and much loss is thus occasioned.

The lad in this factory who had been previously engaged in Kennedy's Lane told us that about six months after he first went to the business he was attacked with toothache, but that he got the tooth extracted, and never had any pain in his jaws or teeth since; he shewed us the tooth, which he carried about with him as a memento ; - it was the second molar in the lower jaw, and was affected with seemingly ordinary caries. We also examined his mouth carefully ; his teeth were all sound, but they were extremely and unnaturally white, of a somewhat diaphanous aspect, and quite free from tartar or other concretion; and we may remark here that the teeth of one of the lads in Mr Reaney's factory, of whom we shall speak particularly hereafter, and who had suffered from symptoms of the malady, presented a precisely similar aspect. A man who was also engaged in dipping in Mr Kelly's, told us that he had been at the work for about three months, that at first the smell made him sick, and did so still if his stomach was empty, and that he had occasionally headache and pains in his jaws and cheek-bones, but not like toothache; his teeth were all sound: this man had evidently heard something of the disease and was apprehensive of being attacked with it. $\mathbf{M r}$ Kelly informed us that the dipping was carried on in his establishment only twice a week, and then for not longer than two hours at a time. The odour of the phosphorus was, we think, much counteracted here by that arising from the vinegar and sulphuric acid employed in making the blacking and ink under the same roof, but was nevertheless very powerful immediately over the heated flag on which the compound was poured. It is right to add, that both the master and the men laid great stress, however, on the use of the camphor as a preventive.

Mr Reaney's factory is devoted solely to the making of lucifer-matches. The rooms, two in number, are large, airy, and well ventilated; about thirty boys, between the ages of six and fourteen years, two lads about nineteen years old, and three men, are constantly employed. None of them, except the two lads, have been engaged in the business for a longer period than five months; these two lads, as before remarked, were employed in one of the Manchester manufactories for seven or eight years. One of them, Hugh Regan, a lad of much intelligence and observation, gave us the following account of himself :- He was employed for more than seven years in the —_ factory, near Manchester ; latterly he had been engaged in dipping, being constantly at it 
every day in the week, and for nearly twelve hours each day, and was paid by piecework; he knew several of those who had lost their jaws in the business, and he recollected some who had died in consequence of the disease.

We tested the correctness of his story, by asking him the names of the persons whom he had known to be affected, when, amongst others, he mentioned those given in Mr Harrison's paper).

He found his own health failing at length; two of his teeth got bad, and one of them he had extracted; the other is still in his mouth, but does not annoy him now.

(This tooth, the second molar in the lower jaw, we examined; it is worn away nearly to the level of the gum, but is not black, nor does it present any hole, and has not the usual appearance of a carious tooth).

He consequently came over to Dublin, and although he has been for the last four months engaged in this factory, he has lost all the symptoms of the disease, nor uoes he apprehend any return of it, as he only dips now on two days in the week, and only for two hours each day; moreover, he says, that the place is more airy, and the smell not so bad.

(No camphor is used in the compound in this factory, and the odour of the phosphorus is much more powerful than in Mr Kelly's, although the room in which the dipping is carried on is much larger).

This lad also told us, that, in England, more girls are affected with the disease than boys or men, although they are not so much exposed to the fumes of the phosphorus as the latter; and this he accounted for by a habit which he said they had of constantly picking their teeth with pins, with the idea of keeping them clean; he said that several of the girls made their teeth bleed every day by thus picking them.

The other lad had been equally long at the business, but in England he was employed in pasting the boxes together, and he followed the same occupation here, with the addition of being occasionally engaged, for a couple of hours at a time, in separating, with his fingers, the matches which adhere together at their points. This is the employment, in which those girls who are described in Mr Harrison's paper as being attacked with the disease, were chiefly engaged; but he has never had the least symptom of it, and his teeth are perfectly sound.

In Mr Reaney's factory, the method of dipping in a large bowl is precisely similar to that followed in England. In both the factories, the operatives are paid by the week, and 
On the Theory of the Action of the Nervus Vagus. 145

not by piece-work; they are all in the enjoyment of robust health, and we heard no complaints of pains in the knees from fatigue, although, with the exception of about half-adozen boys, they all work standing. The hours of work are from seven in the morning until seven at night, two hours being allowed for meals, which are eaten at their own homes.

In conclusion, we have but little to add to the admirable suggestions contained in Mr Harrison's paper as to the prophylaxis of this afflicting disease. Our observations practically bear out the importance of proper ventilation, and from them we think may also be deduced the great advantage which would be derived from a division of labour, so that none of the employed should be exposed to the phosphorus fumes for a longer period " than two hours at a time for two days in the week," the plan followed in the Dublin manufactories.]

ART. IX.-Upon the Theory of the Operation of the Nervus Vagus. By C. EckHARD, of Giessen. (Muller's Archiv fur Anatomie, Physiologie, und Wissenschaftliche Medicin, Jahrgang 1851- Heft iii., seite 205.)

Any one who calmly considers the reason which Volkmann in his Haemodynamik (page $378 \mathrm{ff}$.) adduces in favour of the hypothesis of Weber, upon the distribution of the Nervus Vagus to the Heart, can scarcely resolve to continue an adherent of the theory of Budgé and Schiff. I further think, that I can produce a new fact which speaks in favour of the hypothesis maintained by Weber, Volkmann, and Ludwig.

In my researches upon the action of chemical agents upon the muscular nerves of the Frog, I found that the solutions of most of the alkaline salts, perhaps of all of them, as the representative of which I will select, in the following remarks, common salt (chloride of sodium), present a very peculiar character. This is, that upon immersing the nerve, there arises according to the irritability of the latter, and the degree of concentration of the solution, after a longer or shorter time, first a vibratory motion in a few fasciculi of the muscles connected. The number of these vibratory motions increases successively, and soon the muscular fibres are all in action, so that not unfrequently they contribute to a general convulsive action. This irregular movement commonly lasts for a quarter of an hour and longer.:

The possible theories which may be proposed upon the action of the substance now mentioned, must be developed in another place. We meanwhile see so much, that this pecu-

VOL. LXXIX. NO. 194. 